\title{
PV Cell Parameters Modeling and Temperature Effect Analysis
}

\author{
Adnan Kabbani * and Mohamed Shaik Honnurvali
}

Department of Electronics and Communication, Asharqiyah University, Ibra, Oman

\begin{abstract}
With the wide acceptance of modeling a PV cell by a single diode, a series and parallel resistors; many researchers have discussed different mathematical forms and iterative techniques to extract the values of these model elements depending on the key parameters provided by the manufacturer datasheet. This paper avoids iterative techniques and obtains the values of the five parameters of the one diode model by developing closed form expressions. The maximum error produced by this technique is $10 \%$ when compared to the exact values of the one diode model circuit built by Spice. The 10\% maximum error has occurred during the estimation of the reverse saturation current (Io) of the diode, nevertheless, it should be mentioned that even for this same parameter the model outperforms many iterative dependent works. Furthermore, this paper discusses the effect of temperature on the operation performance of PV cells. In particular, the temperature effect on the open circuit voltage, the short circuit current, the fill factor, the reverse saturation current, and the conversion efficiency was modeled and evaluated for different brand technologies.
\end{abstract}

Keywords: PV cells, PV- modules, one diode model, five parameters, open circuit voltage, short circuit, fill factor, reverse saturation current

Article History: Received: 30th Oct 2020; Revised: 20th February 2021 ; Accepted: 10 ${ }^{\text {st }}$ March 2021; Available online: $20^{\text {th }}$ March 2021

How to Cite This Article: Kabbani, A. and Honnurvali, M.S. (2021) PV Cell Parameters Modeling and Temperature Effect Analysis. International Journal of Renewable Energy Development, 10(3), 563-571.

https://doi.org/10.14710/ijred.2021.33845

\section{Introduction}

Solar energy is becoming one of the most important sources of energy and it is expected that its share of globally produced energy will grow fast. Thus, there is a need for continuous development of PV cells at the implantation level which ranges from different materials to different fabrication techniques. All aim at improving the efficiency of light conversion to electrical current. On the utilization level, the performance of a PV cell may be improved by operating it at optimal conditions which requires a full understanding of its behavior. In addition, it helps in the prediction of the performance under different operating conditions.

To have a good insight on the behavior of a PV cell, the cell should be modeled accurately and the parameters of the equivalent circuit have to be predicted precisely. The problem of modeling PV cells has been tackled by many researchers for many years. In fact, researchers have introduced different circuit models for PV cells; these models have various degrees of complexity and accuracy. The simplest PV cell model is the ideal model which consists of a current source and a diode (Cuce et al. 2013; Piazza et al. 2009; Rodrigues et al. 2011; Luque et al. 2003) as illustrated in Fig. 1. The current source accounts for current generated by the incidence of light $\left(I_{P h}\right)$ which depends mainly on the solar irradiance. The diode represents the recombination current in the quasi-neutral regions.
To improve the model accuracy, the cell's internal resistance is accounted for by adding a series resistance Rs which represents the effect of the semiconductor layers ( $\mathrm{p}$ and $\mathrm{n}$ layers), the contacts and the metal connections (Wolf et al. 1963). Additionally, the leakage current is modeled by adding a parallel resistance $R_{p}$. Fig. 2 shows the schematic of this model which has been adopted by many researchers (Fesharaki et al. 2011; Petreus et al. 2011; and Sabadus et al. 2017). The value of $R_{p}$ is high for good cells, but for defective ones the value of $R_{p}$ is usually low. The impact of low value $R_{p}$ is more significant when $I_{p h}$ is small i.e., when the irradiance levels are low since $I$ will be low and consequently the produced power will also be low.

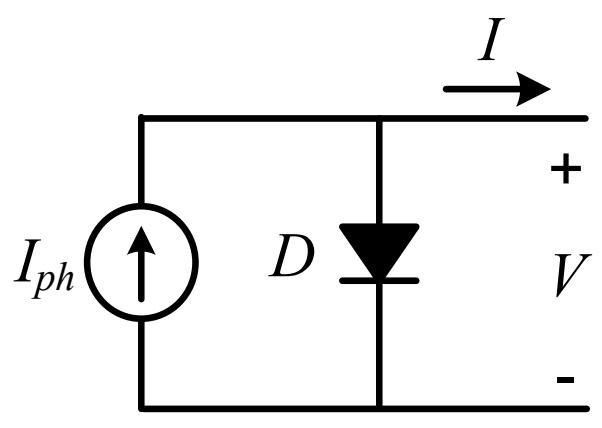

Fig. 1. The ideal model of a PV cell. 


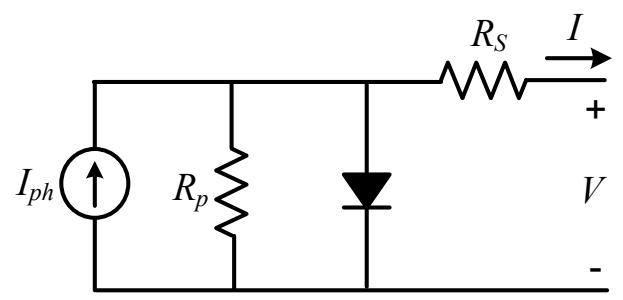

Fig. 2. The one diode model of a PV cell.

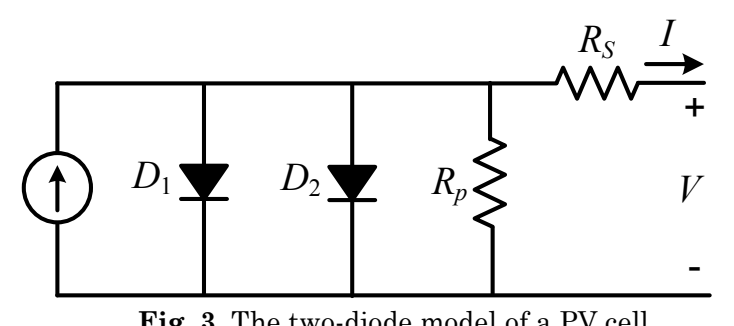

Fig. 3. The two-diode model of a PV cell

A more accurate and more complicated model was introduced in (Sah et al; 1957). In this model a second diode is added on parallel as presented in Fig. 3 to reflect the effect of the recombination current in the depletion region.

A comparison study has been conducted to compare the performance between the one-diode and two-diode models (Bouraiou et al. 2015). Experimental and simulated results showed that there is a very limited accuracy difference between the two models. And with the consideration of the reduced complexity of one-diode model compared to the two-diode model, this work finds closed form expressions for the five parameters (namely $R_{s}, R_{p}, I_{p h}, I_{o}$, and $n$ ) of the one-diode model depending on the data provided by the datasheet.

Considering the one-diode model shown in Fig. 2, the following well-known equation 1 can be introduced

$$
I=I_{p h}-I_{o}\left[e^{\left(\frac{V+I R_{s}}{n V_{t}}\right)}-1\right]-\frac{V+I R_{s}}{R_{p}}
$$

Where $I$ is the output current of the PV cell, $V$ is the output voltage of the PV cell, $I_{o}$ is the reverse saturation current of the diode, $n$ is the diode ideality factor, $V_{t}=k T / q$ is the thermal voltage where $k$ is the Boltzmann constant and is equal to $1.38 \times 10^{-23}$ Joules/K, $T$ is the absolute temperature of the $\mathrm{p}-\mathrm{n}$ junction in Kelvins and is equal to $273+$ temperature in ${ }^{\circ} \mathrm{C}$ and $q$ is the magnitude of charge of an electron and is equal to $1.6 \times 10^{-19}$ Coulombs.

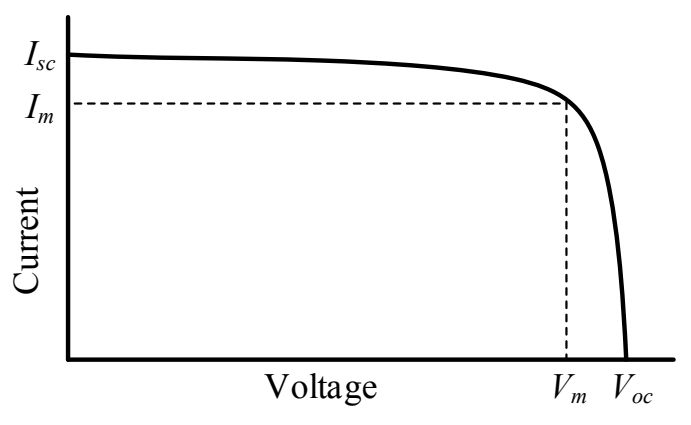

Fig. 4. I-V characteristics of a PV cell
Usually, a datasheet of the PV cells lists three notable parameters on the current-voltage (I-V) characteristic: $V_{o c}$, $I_{s c}$ (the output open circuit voltage and the short circuit output current respectively) and the maximum power $P_{m}$ point which is determined by $V_{m}$ and $I_{m}$ as shown in Fig. 4. Depending on these parameters specified in the datasheets, the five parameters of the single diode model are obtained.

Extracting the five parameters from the single diode model has been tackled by many researchers. To extract the five parameters, the authors of (Blas et al. 2002; Brano et al. 2013; and Chan et al. 1986) have introduced two additional parameters, $R_{s o}$ and $R_{\text {sho, which are the }}$ reciprocal of the gradient at the open-circuit and short circuit points respectively. In (Blas et al. 2002; and Brano et al. 2013) a set of equations has been developed to be solved simultaneously to extract the five parameters while in (Chan et al. 1986), a linear approximation around $V_{o c}$ and $I_{s c}$ was used to find the $R_{s o}$ and $R_{o s h}$.

The five parameters were extracted in (Appelbaum et al. 2014; and Sabadus et al. 2018) by utilizing NewtonRaphson Method to solve the produced equations. A systematic method for extracting the five parameters was proposed in (Zhu et al. 2011). This method depends on analyzing the sensitivity of the parameters which are bounded by a specific range for each. The five parameters were predicted using Matlab/Simulink in (Bellia et al. 2014) where a detailed Simulink model was built for each parameter e.g., $I_{p h}, I_{o}$, etc.

All of the above-mentioned methods depend on some kind of iteration technique to extract the values of the five parameters. Nevertheless, the work in this paper develops closed form analytical expressions for each of the parameters which simplifies the calculations and gives insight on the affecting factors.

\section{Extracting the circuit parameters}

\subsection{The value of $R s$}

For the short circuit condition, the output voltage $V=0$ and thus the voltage across the diode is equal to $I_{s c} \times R_{s}$ which is a very small voltage to turn the diode fully on. The expression developed in (Sabadus et al. 2017) to calculate $R_{s}$ depending on $V_{o c}, I_{m}, V_{m}$ and $I_{s c}$ is adopted in this paper since it depends only on the datasheet information and it shows a good accuracy when compared with Spice simulation results.

$$
R_{S}=\frac{V_{m}\left(\frac{I_{S c}}{I_{m}}-1\right)+\frac{V_{o c}-V_{m}}{\ln \left(1-\frac{I_{m}}{I_{S C}}\right)}}{I_{S c}-I_{m}+\frac{I_{m}}{\ln \left(1-\frac{I_{m}}{I_{S C}}\right)}}
$$

\subsection{The value of the ideality factor $n$}

For the open circuit condition, where the output voltage $V=V_{o c}$, the current through $R_{p}$ is a multi-magnitude less than that of the diode current where the diode will be fully on in this case. Therefore, using the expression in (1) at the open circuit condition, the diode current $I_{d o c}$ can be approximated as stated in Eq (3). 
$I_{d o c} \approx I_{s c}=I_{o} e^{\left(\frac{V_{o c}}{n V_{t}}\right)}$

Again, the current through $R_{p}$ at the maximum power condition $\left.\left(\left(V_{m}+I_{m} R_{s}\right) / R_{p}\right)\right)$ is very small in comparison to $I_{m}$ and $I_{s c}$, so the diode current at the maximum power condition $I_{m d}$ can be approximated as

$$
I_{m d} \approx I_{s c}-I_{m}=I_{o} e^{\left(\frac{V_{m}+I_{s c} R_{s}}{n V_{t}}\right)}
$$

By taking the ratio of (3) over (4) the following expression is obtained

$$
\frac{I_{S c}}{I_{s c}-I_{m}}=e^{\left(\frac{V_{o c}-V_{m}+I_{s c} R_{S}}{n V_{t}}\right)}
$$

The expression in (5) has only $n$ as an unknown variable, solving (5) for $n$ yields

$$
n=\frac{I_{S c} R_{S}+V_{m}-V_{o c}}{\ln \left(\frac{I_{S C}-I_{m}}{I_{S c}}\right) V_{t}}
$$

The expression in (6) estimates the value of the diode quality as a function of $I_{m}, V_{m}, I_{s c}$ and $V_{o c}$, which are given by the datasheet and $R_{s}$ which has been estimated earlier in (2).

\subsection{The value of the diode reverse saturation current $I_{o}$}

Since the value of $n$ is known, the value of $I_{o}$ can be simply found by substituting the value of $n$ as obtained from (6) in (3) and solving for $I_{o}$.

$$
I_{o}=\frac{I_{S C}}{e^{\left(\frac{V_{O C}}{n V_{t}}\right)}}
$$

\subsection{The value of the parallel resistance $R_{p}$}

The value of $R_{p}$ can be estimated by applying (1) at the maximum power point.

$$
I_{m} \approx I_{s c}-I_{o} e^{\left(\frac{V_{m}+I_{m} R_{s}}{n V_{t}}\right)}-\frac{V_{m}+I_{m} R_{s}}{R_{p}}
$$

In (8), all of the values except $R_{p}$ are either provided by the data sheets or have been found through the previous equations and as such solving (8) for $R_{p}$ gives

$$
R_{p} \approx \frac{V_{m}+I_{s c} R_{S}}{I_{s c}-I_{m}-I_{o} e^{\left(\frac{V_{m}+I_{m} R_{s}}{n V_{t}}\right)}}
$$

\subsection{The value of the current generated by the incidence of light $I_{p h}$}

With $R_{p}$ specified, and since during the derivation of the five parameters, $I_{s c}$ is considered to be equal to $I_{p h}$, thus from Fig. 2 the actual value of $I_{p h}$ can be given as

$$
I_{p h}=I_{s c}+\frac{I_{s c} R_{S}}{R_{p}}=I_{s c}\left(1+\frac{R_{S}}{R_{p}}\right)
$$

From (Eq 10), it is clear that the error $E_{I p h}$ produced by approximating the $I_{p h}$ with $I_{s c}$ can be estimated as

$E_{I p h} \%=\frac{R_{S}}{R_{p}+R_{S}}$

According to (11), the margin for error introduced in (10) will be very small since the ratio of $R_{s} / R_{p}$ is very small.

\section{Simulation and result discussion}

Since it has been proven that the one diode model represents the behavior of PV cells, thus in order to verify the accuracy of the developed expressions we compare them to the simulation results of the one-diode model. For the simulation to be realistic, the values of $I_{o}, R_{s}, n$ and $R_{p}$, are chosen to be close to those measured (the value of $n$ has been estimated not measured) in (Sabadus et al. 2017) as such we built the circuit in Fig. 5 .

The circuit has been simulated to obtain the performance values that are usually provided by the datasheet i.e. $I_{s c}, V_{o c}, I_{m}$ and $V_{m}$. The datasheet parameters, as obtained from Spice simulation of the PV cell model-circuit in Fig. 5 are as follows: $I_{s c}=0.1500 \mathrm{~A}$, $V_{o c}=0.6200 \mathrm{~V}, V_{m}=0.5000 \mathrm{~V}$, and $I_{m}=0.1371 \mathrm{~A}$. Based on the simulated datasheet performance values, the values of $R_{s}$, $n, I_{o}, R_{p}$ and $I_{p h}$ are calculated according to equations (2), (6), (7), (9), and (10) respectively. Afterward, the computed values are compared with the original values used in the one-diode circuit in Fig. 5 to determine the accuracy of the model.

The results presented in Table 1 show that the proposed models provide a good accuracy with the maximum error of $10 \%$ occurring for the calculation of $I_{o}$ which outperforms the accuracy presented in (Sabadus et al. 2017). Although the work in (Sabadus et al. 2017) provided better accuracy for $R_{s}$, it doesn't estimate any value for $R_{p}$. Moreover, parameter evaluations in (Sabadus et al. 2017) depend on iterative Newton-Raphson method while the proposed models don't need any iteration. The error of the estimated value of the light generated current is zero as shown in Table 1. In fact, there is a very small error since the estimated value is $0.1500019972 \mathrm{~A}$, and not $0.1500 \mathrm{~A}$ exactly. According to the obtained values of $R_{s}$ and $R_{p}$ the value of $E_{I p h}$ as given by (11) is $1.1 \times 10^{-3} \%$ for the actual values and $1.3 \times 10^{-3} \%$ for the estimated values.

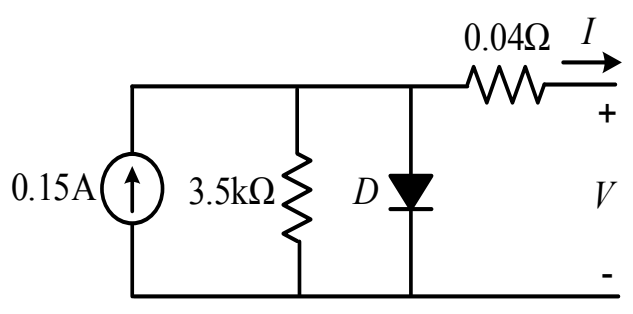

Fig. 5. The model circuit simulated with Spice. 
Table 1

The actual and estimated parameters of circuit model considered in this work.

\begin{tabular}{lccccc} 
& $\boldsymbol{R}_{\boldsymbol{s}}$ & $\boldsymbol{n}$ & $\boldsymbol{I}_{\boldsymbol{o}}$ & $\boldsymbol{R}_{\boldsymbol{p}}$ & $\boldsymbol{I}_{\boldsymbol{p h}}$ \\
& {$[\boldsymbol{\Omega}]$} & & {$[\mathrm{nA}]$} & {$[\mathrm{k} \boldsymbol{\Omega}]$} & {$[\mathrm{A}]$} \\
\hline Actual & 0.040 & 1.800 & 252.00 & 3.500 & 0.1500 \\
Estimated & 0.043 & 1.801 & 226.55 & 3.260 & 0.1500 \\
Error\% & 7.5 & 0.05 & 10 & 6.9 & 0 \\
Error\% (Sabadus et al. 2017) & 0 & $\mathrm{NA}$ & 78 & $\mathrm{NA}$ & 0 \\
\hline
\end{tabular}

Table 2

The actual and estimated parameters of circuit model considered in this work.

\begin{tabular}{llcccc}
\hline & $\boldsymbol{R}_{\boldsymbol{s}}[\mathbf{m} \boldsymbol{\Omega}]$ & $\mathbf{n}$ & $\boldsymbol{I}_{\boldsymbol{o}}[\boldsymbol{n A}]$ & $\boldsymbol{R}_{\boldsymbol{p}}[\mathbf{\Omega}]$ & $\boldsymbol{I}_{p h}[\mathbf{m A}]$ \\
\hline Actual & 0.038 & 1.4885 & 323.3 & 125.0 & $I_{p h}=761.0$ \\
& & & & & $@ I_{s c}=760.8$ \\
This work & 35.00 & 1.4885 & 323.3 & 130.0 & $\begin{array}{l}I_{p h}=761.45 \\
\text { TRR }\end{array}$ \\
ABSO & 36.34 & 1.4738 & 300.4 & 44.08 & $I_{s c}=760.8$ \\
BMO & 36.95 & 1.4758 & 306.2 & 52.29 & $I_{s c}=761.9$ \\
GA & 36.36 & 1.4817 & 324.8 & 53.87 & $I_{s c}=760.8$ \\
HS & 29.90 & 1.5751 & 808.7 & 42.37 & $I_{s c}=761.9$ \\
GGSH & 36.63 & 1.4754 & 305.0 & 53.59 & $I_{s c}=760.7$ \\
IGHS & 36.31 & 1.4822 & 326.2 & 53.06 & $I_{s c}=760.9$ \\
PS & 36.13 & 1.4874 & 343.5 & 53.28 & $I_{s c}=760.8$ \\
SA & 31.30 & 1.6000 & 998.0 & 64.10 & $I_{s c}=761.7$ \\
NILSO & 34.50 & 1.5172 & 479.8 & 43.10 & $I_{s c}=762.0$ \\
\hline
\end{tabular}

The developed model has been verified further by targeting an old technology (Easwarakhanthan et al. 1986) which is considered by many researchers as listed in (Li et al. 2016). We have chosen this technology due to the fact that its parameters are significantly different from the one considered in (Sabadus et al. 2017). Of particular importance is the value of $R_{p}$ which has been estimated by previous works, as presented in Table 2 , to be in the range between $40-60 \Omega$.

The results illustrated in Table 2 show that the proposed model provides a very good agreement with the simulated results and it outperforms many of the previously published works. Nevertheless, the value of $R_{p}$ seems to be very much overestimated by the model, however when compared with the simulated value it shows a good agreement. To further verify the effect of $R_{p}$, we changed its value over a wide range from $50 \Omega$ to $150 \Omega$, during which the variations of the values of $I_{m}, V_{m}, V_{o c}$ and $I_{s c}$ were very minor. The largest variation is in $V_{o c}$ value and it is $<0.4 \%$.

\section{Modelling and discussion of temperature effect on the PV cell performance}

The effect of temperature on the PV cell operation has been studied extensively by many researchers (Fesharaki et al. 2011; Petreus et al. 2008; Easwarakhanthan et al.
1986; Dzimano 2008; Ishaque et al. 2011; and Femia et al. 2013). In the following subsections we study the influence of the cell's temperature on its open circuit voltage, short circuit current, fill factor, reverse saturation current and conversion efficiency.

\subsection{The open circuit voltage}

In (Fesharaki et al. 2011; Petreus et al. 2008; Dzimano 2008; Ishaque et al. 2011; and Femia et al. 2013) the PV cells I-V characteristics are plotted for different cell temperatures. The curves show that the effect of the temperature on the short circuit current $I_{s c}$ is negligible while its impact on the open circuit voltage is significant. In Fig. 6 we reproduce the I-V curves introduced in (Fesharaki et al. 2011; Petreus et al. 2008; Dzimano 2008; Ishaque et al. 2011; and Femia et al. 2013) where the open circuit voltage has been plotted as a function to the cell temperature. In Fig. 6, we have normalized the cell's temperature to its maximum temperature $\left(T_{\max }\right)$ as provided by the considered reference; and the open circuit to its value at the standard temperature $\left(V_{o c n}\right)$. These curves show that there is a nearly linear relationship between the temperature $T / T_{\max }$ and $V_{o c} / V_{o c n}$, as such we may express $V_{o c}$ as

$$
V_{o c}=V_{o c n}+K_{v}\left(T-T_{n}\right)
$$


Where $K_{v}=\frac{\Delta V_{o c}}{\Delta T}$ represents the slope of the considered curve in Fig. 6 and it is usually provided by the manufacturer as the open circuit voltage coefficient. In fact, $K_{v}$ represents the sensitivity of the open circuit voltage of a cell to its temperature variation. $\Delta V_{o c}$ is the open circuit voltage change when the cell temperature changes by $\Delta \mathrm{T}$.

Following the same arguments, the effect of the temperature on the short circuit current can be modeled as

$$
I_{s c}=I_{s c n}+K_{i}\left(T-T_{n}\right)
$$

Where $K_{i}=\frac{\Delta I_{s c}}{\Delta T}$, and $I_{s c n}$ is value of the short circuit current at the standard temperature. To investigate the results presented in (Fesharaki et al. 2011; Petreus et al. 2008; Dzimano 2008; Ishaque et al. 2011; and Femia et al. 2013), we used the expression in (13) to plot $I_{s c}$ as a function of temperature for different PV cell brand technologies as illustrated in Fig. 7.

Clearly the obtained current plots in the previous figure demonstrate the minor effect of the temperature on the short circuit current.

\subsection{The fill factor}

The Fill Factor $(F F)$ is an important index of the quality of a PV cell since it shows the cell's ability to produce energy (Dzimano 2008; and Femia et al. 2013). FF is defined as the ratio of the maximum power $\left(P_{m}=I_{m} . V_{m}\right)$ of a PV cell to its $V_{o c}$ and $I_{s c}$ product (Dzimano 2008; and Femia et al. 2013).

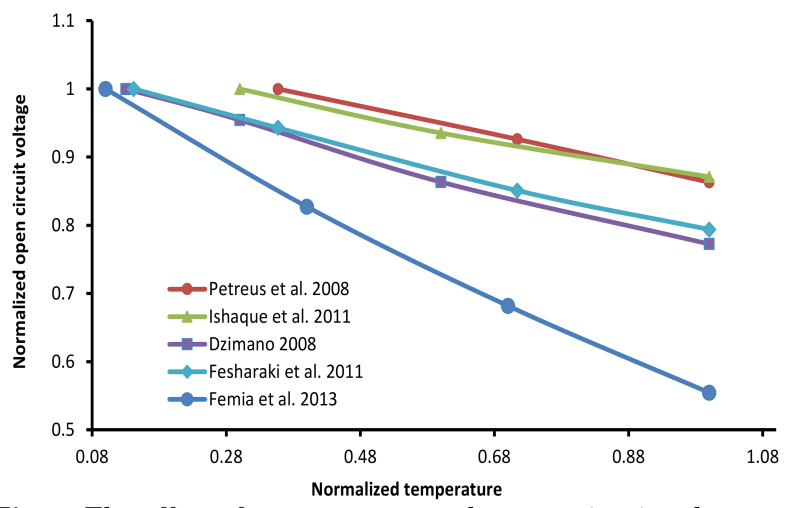

Fig. 6. The effect of temperature on the open circuit voltage.

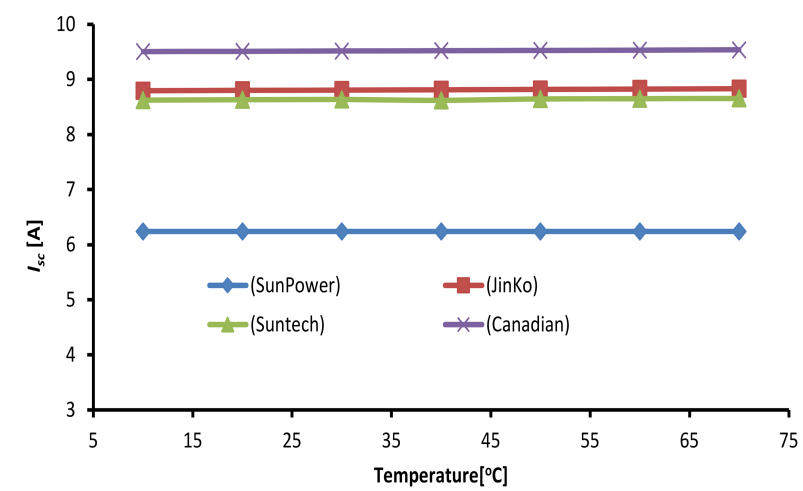

Fig. 7. The effect of temperature on the short circuit current.

$$
F F=\frac{I_{m} V_{m}}{I_{S c} V_{o c}}=\frac{P_{m}}{I_{s c} V_{o c}}
$$

As it is apparent from (14), the variation of $F F$ with the temperature depends on the variation of the maximum power, the short circuit current and the open circuit voltage. The variation coefficients of these parameters are provided by the manufacturers.

$$
F F=\frac{P_{m}+K_{p}\left(T-T_{n}\right)}{\left[I_{s c}+K_{i}\left(T-T_{n}\right)\right]\left[V_{o c}+K_{v}\left(T-T_{n}\right)\right]}
$$

Where $K_{p}=\frac{\Delta P_{m}}{\Delta T}$ and $K_{i}=\frac{\Delta I_{s c}}{\Delta T}$ are given by the datasheet as the Temperature Coefficient of the maximum power and the Temperature Coefficient of the short circuit current. Compared to $K_{v}$, the value of $K_{i}$ is very small as showed in Table 3 where the values of $K_{i}$ and $K_{v}$ are presented for different manufacturers.

Equation (15) is valid if the coefficients are given as voltage/current per ${ }^{\circ} \mathrm{C}$ (e.g., the SunPower case in Table 3 ), but if these coefficients are given as a percentage, then (15) should be rewritten to be

$F F=\frac{P_{m}\left(1+K_{p}\left(T-T_{n}\right)\right)}{\left[I_{s c}\left(1+K_{i}\left(T-T_{n}\right)\right)\right]\left[V_{o c}\left(1+K_{v}\left(T-T_{n}\right)\right)\right]}$

Using Eq (15) and Eq (16) FF is plotted against the temperature for different PV cell brand technologies as presented in Fig. 8

Fig. 8 shows that the $F F$ s of the considered brand technologies change with temperature at different paces. For example, SunPower outperforms the other three technologies for cell temperatures below $40^{\circ} \mathrm{C}$, but its $F F$ drops faster than others as the temperature increases. On the other hand, Canadian Solar seems to have more stable values of $F F$ as the cell temperature changes.

As illustrated in Fig.6, $V_{o c}$ varies significantly with temperature, however Fig. 7 shows that $I_{s c}$ current is practically stable against the change of temperature. Therefore, the change of $F F$ as a function of temperature is mainly due to the variability of $V_{o c}$.

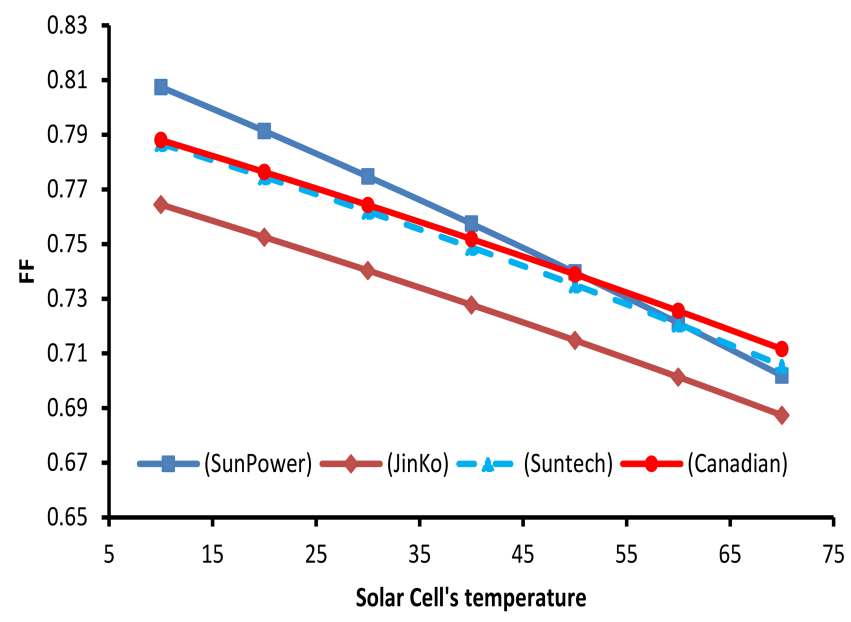

Fig. 8. The Fill Factor as a function of temperature change for different PV cell technologies as obtained by (15) and (16). 
Table 3

The values of the temperature coefficient of the open circuit voltage and the temperature coefficient of the short circuit current as provideded by different manufactureres

\begin{tabular}{ccccc}
\hline & $\begin{array}{c}\text { SunPower } \\
(\text { SunPower) }\end{array}$ & $\begin{array}{c}\text { JinKo Solar } \\
(\text { JinKo) }\end{array}$ & $\begin{array}{c}\text { Suntech Power } \\
\text { (Suntech) }\end{array}$ & $\begin{array}{c}\text { Canadian Solar } \\
\text { (Canadian) }\end{array}$ \\
\hline$K_{v}$ & $-176.6 \mathrm{mV} /{ }^{\circ} \mathrm{C}$ & $-0.31 \% /{ }^{\circ} \mathrm{C}$ & $-0.34 \% /{ }^{\circ} \mathrm{C}$ & $-0.31 \% /{ }^{\circ} \mathrm{C}$ \\
$K_{i}$ & $3.5 \mathrm{~mA} /{ }^{\circ} \mathrm{C}$ & $0.06 \% /{ }^{\circ} \mathrm{C}$ & $0.050 \% /{ }^{\circ} \mathrm{C}$ & $0.053 \% /{ }^{\circ} \mathrm{C}$ \\
$K_{p}$ & $-0.38 \% /{ }^{\circ} \mathrm{C}$ & $-0.41 \% /{ }^{\circ} \mathrm{C}$ & $-0.45 \% /{ }^{\circ} \mathrm{C}$ & $-0.41 \% /{ }^{\circ} \mathrm{C}$ \\
$V_{o c}$ & 64.9 & 45.3 & 37.4 & 38.6 \\
$I_{s c}$ & 6.46 & 8.8 & 8.63 & 9.51 \\
$P_{m}$ & 327 & 300 & 250 & 285 \\
\hline
\end{tabular}

Table 4

The relative error produced as a result of linearizing the relationship between $\mathrm{FF}$ and cell temperature

\begin{tabular}{|c|c|c|c|c|c|c|c|c|}
\hline \multirow{4}{*}{ 这 } & Cell Temperature $\left[{ }^{\circ} \mathrm{C}\right]$ & 10 & 20 & 30 & 40 & 50 & 60 & 70 \\
\hline & SunPower (SunPower) & 0.03 & 0.00 & 0.04 & 0.15 & 0.36 & 0.67 & 1.09 \\
\hline & JinKo Solar (JinKo) & 0.02 & 0.00 & 0.02 & 0.10 & 0.23 & 0.43 & 0.72 \\
\hline & Suntech Power (Suntech) & 0.03 & 0.00 & 0.03 & 0.13 & 0.31 & 0.59 & 0.99 \\
\hline & Canadian Solar (Canadian) & 0.02 & 0.00 & 0.02 & 0.10 & 0.24 & 0.46 & 0.76 \\
\hline
\end{tabular}

Although it is clear from (15) and (16) that the relationship between $F F$ and the cell temperature is not linear, Fig. 8 suggests that this relationship is very close to being a linear one as presented in (Femia et al. 2013).

Equation (16) may be linearized by using Taylor Series around $T=T_{n}$ and limiting the series to two terms which yields

$F F=F F_{n}+F F_{n}\left(K_{p}-K_{i}-K_{v}\right)\left(T-T_{n}\right)$

Where $F F_{n}$ is the value of the Fill Factor at the standard temperature. The accuracy is evaluated by comparing the results obtained by Eq (15) or Eq (16) and the linear equation (17) as presented in Table 4. The error in Table 4 is calculated using Eq (18)

Error $\%=\frac{\left|F F_{15,16}-F F_{17}\right|}{F F_{15,16}} \times 100$

Where $F F_{15,16}$ and $F F_{17}$ are the values of the Fill Factor as obtained by Eqs (15) or (16) and (17) respectively.

Table 4 shows that the error produced by expressing $F F$ as a linear function of temperature is very small (the maximum error is $1.09 \%$ ), thus $\mathrm{Eq}$ (17) can be used to estimate $F F$ for different values of temperature with a very good accuracy. Actually, Eq (17) can be rewritten as

$$
F F=F F_{n}+K_{f}\left(T-T_{n}\right)
$$

Where $K_{f}$ is the temperature coefficient of the Fill Factor and it is expressed as
Table 5

The values of the temperature coefficient of the Fill Factor for different technologies as estimated by (20).

\begin{tabular}{lllll}
\hline & $\begin{array}{l}\text { SunPower } \\
\text { (SunPower) }\end{array}$ & $\begin{array}{l}\text { JinKo } \\
\text { Solar } \\
\text { (JinKo) }\end{array}$ & $\begin{array}{l}\text { Suntech } \\
\text { Power } \\
\text { (Suntech) }\end{array}$ & $\begin{array}{l}\text { Canadian } \\
\text { Solar } \\
\text { (Canadian) }\end{array}$ \\
\hline$K_{f}$ & 0.00193114 & 0.001223111 & 0.001258781 & 0.00120578 \\
\hline
\end{tabular}

$K_{f}=F F_{n}\left(K_{p}-K_{i}-K_{v}\right)$

In Table 4 the values of the previously considered technologies are calculated using Eq (20). Table 5 reflects the fact that SunPower has the highest value of $K_{f}$ which is compatible with the conclusion drawn from Fig. 8 .

Furthermore, Eq (19) can be used to check the stability of the Fill Factor of PV cells against temperature. We can notice easily that this stability increases as $K_{f}$ approaches zero which yields that $K_{p}$ converges to the algebraic sum of $K_{v}$ and $K_{i}$. It should be noted that $K_{p}, K_{v}$ and $K_{i}$ must be expressed as percent values i.e., $\% /{ }^{\circ} \mathrm{C}$.

\subsection{The reverse saturation current}

Considering the model presented in Fig. 1, we can see clearly that the temperature affects the current generated by the incidence of light $I_{p h}$ and the diode current $I_{d}$. 
Utilizing the approximation of $I_{p h}=I_{s c}$, we can express the value of the short circuit current $I_{s c n}$ at the temperature of the standard condition $\left(T_{n}\right)$ as

$I_{s c n}=I_{o n} e^{\left(\frac{V_{o c n}}{n V_{t n}}\right)}$

Where $I_{o n}$ is the reverse saturation current of the diode at $T_{n}, V_{t n}$ is the thermal voltage and is given as $V_{t n}=k T_{n} / q$. Let $I_{s c}$ be the short circuit current at the actual temperature $T$ as defined before.

$I_{s c}=I_{o} e^{\left(\frac{V_{o c}}{n V_{t}}\right)}$

Considering that the change in $I_{s c}$ due to the temperature change is insignificant as stated previously, then we can write

$$
I_{s c}=I_{s c n}
$$

And consequently

$$
I_{o} e^{\left(\frac{V_{o c}}{n V_{t}}\right)}=I_{o n} e^{\left(\frac{V_{o c n}}{n V_{t n}}\right)}
$$

Solving (23) for $I_{o}$ gives

$$
I_{o}=I_{o n} e^{\left(\frac{V_{o c n}}{n V_{t n}}-\frac{V_{o c}}{n V_{t}}\right)}
$$

According to Eq (24), the reverse saturation current is influenced by the cell temperature through the thermal voltage and the open circuit voltage. Thus, to find the value of $I_{o}$ as a function of temperature we replace $V_{t}$ by $k T_{n} / q$ and $V_{o c}$ by its expression from Eq (12) which yields

$$
I_{o}=I_{o n} e^{\left(\frac{V_{o c n}+T_{n} K_{v}}{n V_{t n}}\right)\left(1-\frac{T_{n}}{T}\right)}
$$

The expression shows that the reverse saturation current increases with the temperature. Nevertheless, as $T_{n} / T \rightarrow 0$, this current saturates and reaches its plateau value estimated by Eq (26)

$$
I_{o}=I_{o n} e^{\frac{q}{n k}\left(\frac{V_{o c n}}{T_{n}}+K_{v}\right)}
$$

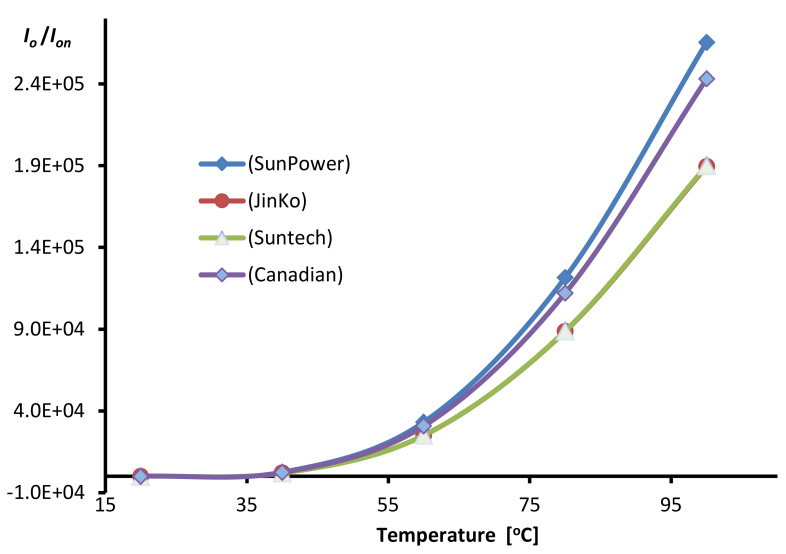

Fig. 9. The reverse saturation current as a function of temperature change for different PV cell brand technologies as obtained by (24).
In Fig. 9 we plot the normalized value of $I_{o} / I_{o n}$ as a function of the temperature for different PV cell brand technologies. The figure shows that for all these technologies the reverse saturation current increases approximately by 200 times as the temperature increases from $20^{\circ} \mathrm{C}$ to $100^{\circ} \mathrm{C}$.

\subsection{The conversion efficiency}

The efficiency of a PV cell is an important criterion that shows the ability of a PV cell to convert the incident light to electricity and is expressed as (Tiwari et al. 2010)

$$
\eta=\frac{P_{m}}{P_{\text {in }}}=\frac{I_{m} V_{m}}{I_{i} A_{c}}=\frac{I_{s c} V_{o c} F F}{I_{i} A_{c}}
$$

The illumination intensity $\left(I_{i}\right)$ and the PV cell/panel area $\left(A_{c}\right)$ are independent of the PV cell temperature, which leaves the dependence of $\eta$ on the temperature to be because of the temperature effect on $I_{s c}, V_{o c}$ and $F F$. As the change of $I_{s c}$ with the temperature is negligible, the change of the value of $\eta$ due to the temperature is therefore mainly because of the variations of $V_{o c}$ and $F F$.

$$
\eta=\frac{P_{m}}{P_{i n}}=\frac{I_{m} V_{m}}{I_{i} A_{c}}=\frac{I_{s c}}{I_{i} A_{c}} V_{o c} F F=\alpha V_{o c} F F
$$

Where

$$
\alpha=\frac{I_{s c}}{I_{i} A_{c}}
$$

Since $I_{s c} \approx I_{p h}$, then a can be seen as the solar panel's conversion efficiency between the illumination intensity and the generated current per unit area.

As a result, the relationship between $\eta$ and the temperature can be developed by replacing the values of $V_{o c}$ and $F F$ from $\mathrm{Eq}(12)$ and $\mathrm{Eq}$ (19) respectively in $\mathrm{Eq}$ (28).

$\eta=\alpha\left(V_{o c n}+K_{v}\left(T-T_{n}\right)\right) \times\left(F F_{n}+K_{f}\left(T-T_{n}\right)\right)$

$\eta=\alpha\left(V_{o c n} F F_{n}+V_{o c n} K_{f}+K_{\eta 1}\left(T-T_{n}\right)+K_{\eta 2}\left(T-T_{n}\right)^{2}\right)$

Where $K_{\eta 1}=\alpha\left(F F_{n} K_{v}+V_{o c} K_{f}\right)$ and $K_{\eta 2}=\alpha K_{v} K_{f}$

The expression in Eq (30) shows that the relationship between the efficiency and the temperature is nonlinear due to the existence of $K_{\eta 2}\left(T-T_{n}\right)^{2}$. Nevertheless, (30) has two other terms: $\alpha V_{o c n} F F_{n}$ and $K_{\eta 1}\left(T-T_{n}\right)$. The first term is a constant that represents the efficiency at the standard temperature; the second term represents a linear relationship between $\eta$ and the temperature.

To further understand the behavior of the efficiency variation with the temperature change, we estimated the impact of $K_{\eta 1}\left(T-T_{n}\right)$ and $K_{\eta 2}\left(T-T_{n}\right)^{2}$ on $\eta$ for different PV cell brand technologies and temperatures as presented in Table 6. Note the values of $K_{\eta 1}$ and $K_{\eta 2}$ are normalized to a. 
Table 6

The impact of $K_{\eta 1}\left(T-T_{n}\right)$ and $K_{\eta 2}\left(T-T_{n}\right)^{2}$ on the efficiency for different PV brand technologies.

\begin{tabular}{|c|c|c|c|c|c|c|c|}
\hline & Brands & $10\left[{ }^{\circ} \mathrm{C}\right]$ & $30\left[{ }^{\circ} \mathrm{C}\right]$ & $40\left[{ }^{\circ} \mathrm{C}\right]$ & $50\left[{ }^{\circ} \mathrm{C}\right]$ & $60\left[{ }^{\circ} \mathrm{C}\right]$ & $70\left[{ }^{\circ} \mathrm{C}\right]$ \\
\hline & SunPower & 0.000 & 0.000 & 0.001 & 0.001 & 0.001 & 0.001 \\
\hline$\overline{\bar{y}}$ & JinKo Solar & 0.001 & 0.001 & 0.001 & 0.002 & 0.003 & 0.003 \\
\hline$\stackrel{F}{F}$ & Suntech Power & 0.001 & 0.001 & 0.002 & 0.002 & 0.003 & 0.004 \\
\hline$\underline{z}$ & Canadian Solar & 0.001 & 0.001 & 0.002 & 0.002 & 0.003 & 0.004 \\
\hline
\end{tabular}

Table 6 shows that the impact of the second order term is insignificant compared to the first order term (about 0.004 at its maximum when the operating temperature is $70^{\circ} \mathrm{C}$ ) and basically, the effect of the temperature on the efficiency is dominated by the first order term i.e., $K_{\eta 1}(T$ $T_{n}$ ). Hence, the effect of the temperature on a PV cell performance can be approximated by

$$
\eta=\eta_{n}+K_{\eta 1}\left(T-T_{n}\right)
$$

Where $\eta_{n}$ is the performance at the standard conditions and $K_{\eta 1}$ is as defined before. It worth mentioning that $K_{\eta 2}$ is positive, i.e., it works toward improving the performance, however, this effect is insignificant as demonstrated in Table 5.

\section{Conclusion}

Closed form expressions have been developed in this paper for estimating the five parameters that form the one-diode model of a PV cell. As a test vehicle, a one-diode model circuit that represents a real-life PV cell has been built and simulated using Spice to extract the information that is usually provided by the datasheet.

The proposed expressions provide good accuracy with a maximum error of $10 \%$ when compared to the model circuit. Although the developed expressions are closed form ones; they are still outperforming many of the published results. The outcome of this work can be used as is to provide a fast calculation; or it can be used to offer excellent estimation of the initial value for iterative methods which helps iterative algorithms to reach a fast convergence when more accuracy is required for some of the parameters.

The effect of the temperature on the cell's performance is tackled by analyzing the behavior of the open circuit voltage, the short circuit current, the reverse saturation current, the fill factor and the efficiency as functions of the temperature. As a result, closed form expressions are developed, each one describing the relationship between the above-mentioned parameters respectively and the cell temperature. All these expressions depend on the values usually provided in the datasheet. All the parameters except for the reverse saturation current, have been approximated to simple linear equations which provide good insight and accuracy. The reverse saturation current shows an exponential dependence on the temperature. The models presented in this paper are indeed simple and suitable for hand calculations, nonetheless they provide a very good accuracy.

\section{References}

Appelbaum, J. and Peled, A. (2014). Parameters extraction of solar cells - A comparative examination of three method," Solar Energy Materials and Solar Cells.122, 164-173.

Bellia, H., Youcef, R., and Fatima, M. (2014). A detailed modeling of photovoltaic module using MATLAB. NRIAG Journal of Astronomy and Geophysics. 3, 53-61.

Blas, M. A. D., Torres, J. L., Prieto, E., and Garcia, A. (2002). Selecting a suitable model for characterizing photovoltaic devices. Renew Energy. 25(3), 371-80.

Bouraiou, A., Hamoudaa, M., Chakerb, A., Sadoka, M., Mostefaouia, M., and Lachtara, S. (2015). Modeling and simulation of photovoltaic module and array based on one and two diode model using Matlab/Simulink. Proceedings of International Conference on Technologies and Materials for Renewable Energy, Environment and Sustainability. 864 877.

Brano, V.L, Ciulla, G. (2013). An efficient analytical approach for obtaining a five parameters model of photovoltaic modules using only reference data. Applied Energy. 111, 894-903.

Canadian Solar, CS6K- 285M, datasheet. https://ledsaves.org/wpcontent/uploads/2020/07/a065d77c48a032e72f11d2f8e239510 d.pdf Accessed Nov. 25. 2019.

Chan, D., Phillips, J., Phang, J. (1986). A comparative study of extraction methods for solar cell model parameters. SolidState Electron. 29(3), 329-37.

Cuce, E., Cuce, P. M. and Bali, T. (2013). An experimental analysis of illumination intensity and temperature dependency of photovoltaic cell parameters. Applied Energy, 111, 374-382.

Dzimano, G. (2008). Modeling of Photovoltaic Systems. Msc. Thesis, the Ohio State University.

Easwarakhanthan, T., Bottin, J., Bouhouch, I., Boutrit, C. (1986). Nonlinear minimization algorithm for determining the solar cell parameters with microcomputers. Int. J. Solar Energy. $4(1), 1-12$

Fesharaki, V.J., Dehghani, M. and Fesharaki, J. J. (2011). The effect of temperature on photovoltaic cell efficiency," Proceedings of the 1st International Conference on Emerging Trends in Energy Conservation - ETEC. 20-21.

Femia, N., Petrone, G., Spagnuolo, G., and Vitelli, M. (2013). Power Electronics and Control Techniques for Maximum 
Energy Harvesting in Photovoltaic Systems. Taylor \& Francis Group.

Ishaque, K., Salam, Z., Taheri, H., and Syafaruddin. (2011). Modeling and simulation of photovoltaic (PV) system during partial shading based on a two-diode model. Simulation Modelling Practice and Theory. 19(7).

JinKo Solar, JKM300P, datasheet. https://www.jinkosolar.com/uploads/5e93f9cc/Eagle\%20JKM3 20-340PP-72-(V)-A3,1-EN.pdf Accessed Nov. 25. 2019.

$\mathrm{Li}$ W., et al., (2016). Six-parameter electrical model for photovoltaic cell/module with compound parabolic concentrator. Solar Energy. 137, 551-563.

Luque, A. and Hegedus, S. (2003). Handbook of photovoltaic science and engineering, John Wiley \& Sons Ltd.

Petreus, D., Farcas, C., and Ciocan, I. (2008) Modelling and simulation of photovoltaic cells. Electronics and Telecommunications, 49(1), 42-47.

Piazza, M. C. D., Ragusa, A., and Vitale, G. (2009). Identification of photovoltaic array model parameters by robust linear regression methods. proceeding of International Conference on Renewable Energies and Power Quality, 143-149.

Rodrigues, E. M. G., Melício, R., Mendes, V. M. F. and Catalão, J. P. S. (2011). Simulation of a solar cell considering single-diode equivalent circuit model. Renewable Energy and Power Quality Journal, 1(9), 369-373.
Sabadus, A., Mihailetchi, V. and Paulescu, M. (2017). Parameters extraction for the one-diode model of a solar cell. Proceedings of AIP Conference 1916.

Sabadus, A., Paulescu, M., and Badescu, V. (2018). Extracting the I-V Characteristics of the PV Modules from the Manufacture's Datasheet. Proceedings of the $5^{\text {th }}$ Conference for Sustainable Energy. 434-442.

Sah, C., Noyce, R. N. and Shockley, W. (1957). Carrier generation and recombination in p-n junctions and p-n junction characteristics. Proceedings of the IRE, 45(9),1228-1243.

SunPower, E20/435 SOLAR PANEL, datatsheet. https://us.sunpower.com/sites/default/files/medialibrary/data-sheets/sunpower-e-series-commercial-solarpanels-e20-435-com-datasheet-521912-revb_1.pdf Accessed Nov. 19.2019 .

Suntech, STP250S-20/Wd, datatsheet. https://datasheetspdf.com/pdf/815622/Suntech/STP250S/1 Accessed Nov. 19.2019

Tiwari, G. N. and Dubey, S. (2010). Fundamentals of Photovoltaic Modules and Their Applications," Indian Institute of Technology, RSC publishing. 99-100.

Wolf, M., and Rauschenbach, H. (1963). Series resistance effects on solar cell measurements. Advanced Energy Conversion, 3(2), 455-479.

Zhu, X.-G.; Fu, Z.-H.; Long, X.-M. (2011). Sensitivity analysis and more accurate solution of photovoltaic solar cell parameters. Solar Energy. 85(2), 393-403. 